\title{
P ROJ E CT REPORT \\ A flying start to health promotion in remote north Queensland, Australia: the development of Royal Flying Doctor Service field days
}

\author{
DJ Harvey ${ }^{1}$, R Williams ${ }^{2}$, K Hill ${ }^{2}$ \\ ${ }^{1}$ James Cook University, Cairns, Queensland, Australia \\ ${ }^{2}$ Royal Flying Doctor Service, Queensland, Australia
}

Submitted: 7 November 2005; Resubmitted: 13 December 2005; Published: 2 March 2006

Harvey DJ, Williams R, Hill K

A flying start to health promotion in remote north Queensland, Australia: the development of Royal Flying Doctor Service field days

Rural and Remote Health 6: 485. (Online), 2006

Available from: http://rrh.deakin.edu.au

A B S T R A C T

Context: The Royal Flying Doctor Service (Queensland Section), Australia, provides health services for remote populations across an area of approximately $600000 \mathrm{~km}^{2}$. The challenge presented to the service was to provide effective health promotion as well as acute clinical services.

Issue: This article describes the development of field days, an initiative based on a capacity building approach to health promotion. Field days have been conducted at station properties, national parks, remote tourist facilities, a roadhouse and country racecourse. They usually consist of a morning interactive workshop based on locally identified health topics followed by an afternoon clinic. A developmental approach has been adopted, with participant feedback from each field day and reflections by health staff informing future field day activities and adjustments in methods of delivery. Between November 2001 and August 2005, 726 adults and 248 children attended 53 field days conducted at 18 remote locations in north Queensland. Evaluation: Participants were asked to rate the overall usefulness, content and quality of the presentations/workshops on a scale from 1 (not useful/poor) to 10 (very useful/very good). Overall, feedback from participants was positive. The average scores were 9.1 for overall usefulness of the day and content of the sessions, and 9.2 for quality of the presentations. Field days demonstrate a flexible health promotion initiative based on a capacity building approach which is rated as useful and appropriate by participants. 
Lessons learned: The implementation of field days has highlighted the importance of building on community and organisational strengths as a means of overcoming skepticism about new services and approaches to health. Methods of delivery that are fun, nonthreatening, practical, locally relevant, culturally appropriate and interactive work best. The development of field day packages containing workshop plans and resources facilitates flexibility and enables the program to be tailored to meet the needs of participants. Workforce planning and development have played a key role in reorienting existing services towards health promotion. Field days can inform the development of locally relevant health promotion initiatives based on a capacity building approach in other remote areas of Australia and internationally.

Key words: Australia, capacity building, health promotion, primary health care.

\section{Context}

Health promotion is a key element of a primary health care approach aimed at building community capacity for health ${ }^{1,2}$. Promoting health in remote areas is challenging, due to distance from health services, social isolation, cultural diversity, attitudes to health and the generally poorer health status in remote areas, compared with urban centres ${ }^{3-5}$. This article recounts the development of Royal Flying Doctor Service (RFDS; Queensland Section) 'field days', an outcome of the reorientation of services provided by the RFDS in remote north Queensland, Australia, towards a capacity building approach to health promotion.

\section{Issue}

\section{Royal Flying Doctor Service field days}

The RFDS is well known in rural and remote Australia as the provider of aeromedical retrieval and transport services, remote medical consultations and RFDS medical chests. The chests contain a range of pharmaceutical and other items which enable the provision of health care in emergency situations. Aeromedical retrieval and transport services are able to respond to calls 24 hours a day, 7 days a week.

Recently, RFDS services in Queensland have been expanded to include women's health, mental health, child and family health, Indigenous community liaison and development, and health promotion. The multidisciplinary team includes medicine, nursing, allied health and aviation. Services are provided on a fly-in, fly-out basis to station properties, national parks, road houses, small rural support towns, mining communities and oilfields, island resorts and Indigenous communities. In some of these locations, the RFDS is the sole provider of medical, child health and mental health services, while in others, it supports health services provided by the state government, non-government organisations and other allied health service providers.

Cairns is one of eight RFDS bases in Queensland. The base services an area of approximately $600000 \mathrm{~km}^{2}$, from the Torres Strait in the north, west to Normanton and south to Mackay using a Beechcraft Super King Air B200 and Pilatus PC 12 aircraft. In line with broader changes in health service planning and delivery, a strategic planning workshop in 1998 identified the need for the service to move beyond biomedical approaches to health promotion. This, along with a clinic review process which identified falling attendance in some remote clinics, provided the impetus for redesigning medical and child health services delivered at station properties, national parks and roadhouses.

Services to these locations were changed from a regular clinical service to a less frequent field day format which is coordinated by a health promotion officer. People from surrounding properties (usually within a one to two hour radius) travel to the field day location for the day's activities. Field days have been conducted in station homesteads, shearer's quarters, roadhouses, national park ranger stations, tourist facilities, outstations and outdoors under the shade of 
a tree. The day commences with a morning tea contributed by the participants. This often coincides with the station morning tea break and provides an opportunity for introductions, meeting neighbours and refreshments for those who have traveled some distance to attend. The field day format consists of a morning interactive workshop which addresses health issues of concern to people living and working in the area, followed by an afternoon medical, child health and/or mental health clinic, depending on community need.

Issues addressed at field days are identified through a number of strategies. The field day coordinator who lives at the site plays a critical role in networking with others in the community, discussing issues with neighbours and liaising with the RFDS health promotion officer. Field days combine presentations, skill building, information sharing, group activities, discussions and practical demonstrations in a workshop format conducted by RFDS staff and guest presenters. Follow up between field days is provided by mailing out videos, information about health issues and grant opportunities, and making referrals.

Since field days commenced in 2001, the workshops have included training in the use of the RFDS medical chests, how to give an injection, communication with the RFDS, and preparation for the landing of an RFDS aircraft. A follow-up workshop develops skills in managing and coordinating common emergencies such as snake bite, falls from horses and motor bike accidents. This workshop involves participants working in small groups on case study scenarios relevant to the location.

Feedback from participants about the need to address men's health issues has resulted in delivery of a general health check based on the Pit Stop men's health package developed by the Gascoyne Public Health Unit in Western Australia ${ }^{6}$. This has led to further healthy lifestyle workshops relating to nutrition and physical activity which address the challenge of isolation and distance in remote areas. At one location, these workshops have involved a healthy rural lifestyles presentation by a medical officer, group discussion of the barriers and opportunities for physical activity in remote areas, as well as a circuit class including boxing and Pilates conducted by a personal trainer. Participants were also encouraged to write a personal fitness plan with the support of the trainer. Other workshop formats have addressed issues such as child safety on farms, skin cancer prevention, and practice in cardiopulmonary resuscitation. Workshops have been conducted in collaboration with staff from the Queensland Ambulance Service, the Far North Queensland Rural Division of General Practice, Family Planning Queensland and Farmsafe Queensland.

More recently, workshops have begun to explore underlying sources of stress in remote areas including drought, finance and family relationships. These workshops are facilitated by Relationships Australia and aim to improve communication and develop problem-solving skills through the exploration of multiple family, business and community roles in remote areas. The workshop program often also includes a topic related to first aid or farm safety which helps to create a 'safe' environment for discussion and interaction.

The flexible field day format allows each workshop to be tailored to meet the unique needs and capacity of each site. At some field day locations, participants are mainly men; while at others family participation is a feature with three generations of some families attending. The North Queensland Remote Area Families Service often conducts a playgroup at field days which have a family focus. As community capacity to identify and analyse health issues has developed, the role of the RFDS has increasingly involved facilitating access to a range of services, skills and information relating to issues identified by communities.

\section{Evaluation of field days}

Each field day is evaluated using both formal and informal feedback. At the conclusion of the morning session, participants are asked to rate the overall usefulness, content and quality of presentations or workshops. Written feedback is sought on further issues to be addressed and follow-up activities (or health issues of interest). The health promotion 
officer also seeks informal oral feedback from participants at the field day. Medical officers, nursing and mental health staff are asked to record their reflections on the day, including any issues of concern, in a field day book. These reflections are fed back to participants by the health promotion officer in order to determine priorities and plan future field days. Participant evaluations are compiled by the health promotion officer and presented to RFDS staff at an annual workshop. The workshop provides an opportunity to reflect on field days and determine any changes to be made, including accessing new sites. Methods of delivery are adjusted based on feedback from participants and reflections by RFDS staff and presenters. A comprehensive photographic record is also made of each field day. Comments by staff and presenters have consistently identified practical activities as a useful means of engaging participants. Comments by staff have included: 'practical situations worked well and get group involvement' and 'practical activities well received with good participation'. Feedback from participants has also highlighted the importance of informality and relevance to the local context, with one participant commenting: 'It's a fun day' and another: 'It's nice to have a lady doctor who understands country living'. This developmental approach has allowed for adjustments to be made in the format and methods of delivery, as well as informing and building on issues being addressed at each site.

Between November 2001 and August 2005, 53 field days involving 726 adults and 248 children were held at 18 different locations. Of the adults, $54 \%$ were female. The 18 locations included 12 pastoral properties, two national parks, two remote tourist facilities, one roadhouse, and one country racecourse. Adult participants were asked to complete the written evaluation form and a response rate of $70.5 \%$ was achieved. Participants were asked to rate the overall usefulness of the day and content of the sessions on a scale of 1 to 10 where 1 is 'not useful' and 10 is 'very useful'. Participants were also asked to rate the quality of the presentations on a scale of 1 to 10 where 1 is 'poor' and 10 is 'very good'. During this period, general health checks utilising the Pit Stop format were conducted at six other field days. These involved 74 adults and 41 children. Data are unavailable for three further field days held during the period.

Overall, feedback from participants was positive. The average score for overall usefulness of field days was 9.1 (range 5-10). The average score for content of the sessions was 9.1 (range 4-10). The average score for the quality of presentations was 9.2 (range 5-10).

\section{Lessons learned}

Implementation of the program has highlighted the importance of staff development in reorienting existing services towards health promotion. Field days are coordinated by a health promotion officer and supported by senior management and base staff. It has required staff training in working with small groups, health promotion and primary health care, together with the acquisition and development of a range of health promotion resources. It has presented challenges in the rostering of staff and necessitated the allocation of specific time to field day preparation.

The concept of field days builds on the strengths of both remote communities and the health service. To many remote communities, the RFDS is a familiar and trusted provider of emergency aeromedical, general practice, mental health and child health services. Familiarity with the staff and service appears to have helped to overcome skepticism about a 'new service'. However, achieving the balanced investment in health promotion, illness prevention, treatment and rehabilitation envisaged in the primary health care approach remains an ongoing challenge shared with many health services. The combined aeromedical and primary health care focus of the RFDS has also facilitated continuity of care, as a doctor or nurse who has been involved in a field day may return to a station for the medical evacuation of a family member. The RFDS has also played a role in introducing and referring new services (such as Relationships Australia) to which people in remote locations may not otherwise have access. 
It has been necessary to work with existing views of health and build slowly in ways that are relevant and nonthreatening, towards broader understandings. Field days build on the informal networks of remote communities, bringing together friends, neighbours and newcomers, as well as creating new networks which are developing specifically around field days. Field days build on the expertise, goodwill, and hospitality that exist in many remote communities. We regard field day coordinators at each site as critical to the success of each field day. Being local residents, they demonstrate the skills and capacity for community development which already exist in remote areas and need to be supported.

Methods of delivery of health promotion activities have developed over time and demonstrate the importance of formative evaluation of each field day. Methods which are fun, non-threatening, practical, locally relevant, culturally appropriate and interactive appear to work best. Evaluations indicate that people attend field days for a range of reasons including increasing confidence and ability to respond to medical emergencies, improving health or preventing disease, to socialize and to support the RFDS. To maximise field day attendance and participation at each field day location, it has been necessary to design a flexible program that has 'something for everyone'. To facilitate this, a number of field day packages have been developed by RFDS staff. The packages contain workshop plans and resources that can be readily incorporated into a field day program, as well as ensuring a consistent and informed approach.

\section{Conclusion}

Field days provide a template for developing locally relevant health promotion activities in remote areas using a capacity building approach. These types of health promotion activities need to be recognised and adequately resourced. Further research is also needed to determine the impact on communities and the sustainability of outcomes. The developmental approach which underpins field days can inform the implementation of health promotion activities within a primary health care framework in other remote areas of Australia and internationally.

\section{Acknowledgements}

The authors would like to thank Fiona Tulip of Tropical Public Health Unit Network, Cairns, Australia, Queensland Health for assistance with data management and analysis.

\section{References}

1. Wass A. Promoting health the primary health care approach, 2nd edn. Marrickville, NSW: Harcourt Australia, 2000.

2. Smith, JD. Australia's rural and remote health a social justice perspective. Croydon, VIC: Tertiary Press, 2004.

3. Strong K, Trickett P, Titulaer I, Bhatia K. Health in rural and remote Australia: The first report of the Australian Institute of Health and Welfare on rural health. Cat no. phe 6. Canberra: Australian Institute of Health and Welfare, 1998.

4. Battye KM, McTaggart K. Development of a model for sustainable delivery of outreach allied health services to remote north-west Queensland, Australia. Rural and Remote Health 3: 194 (Online) 2003. Available: http://rrh.deakin.edu.au (Accessed 8 July 2005).

5. Elliott-Schmidt R, Strong J. The concept of well-being in a rural setting: understanding health and illness. Australian Journal of Rural Health 1997; 5: 59-63.

6. Hall, C, Alston E. Pit Stop men's health package. Carnarvon, WA: Gascoyne Public Health Unit,1999. 